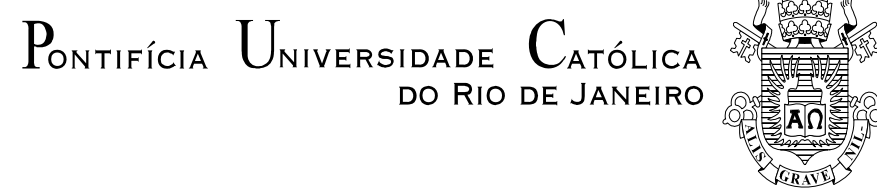

Lucía Yáñez Silva

\title{
O RUMOR DO CORPO NA DERIVA DAS PALAVRAS: \\ uma reflexão sobre as relações entre o corpo e a escrita a partir do trabalho de Juan Dominguez
}

Tese de Doutorado

Tese apresentada ao Programa de Pós-Graduação em História Social da Cultura do Departamento de História da PUC-Rio como parte dos requisitos parciais para obtenção do título de Doutor em História.

Orientadora: Prof. ${ }^{a}$ Cecília Martins de Mello

Rio de Janeiro

Agosto de 2010 


$$
\text { Pontifícia } \underbrace{}_{\text {niversidade }} \text { Católica }_{\text {Do Rio de Janeiro }}
$$

Lucía Yáñez Silva

\begin{abstract}
O rumor do corpo na deriva das palavras: uma reflexão sobre as relações entre o corpo e a escrita a partir do trabalho de Juan Dominguez
\end{abstract}

\begin{abstract}
Tese apresentada como requisito parcial para obtenção do grau de Doutor pelo Programa de Pós-Graduação em História Social da Cultura do Departamento de História do Centro de Ciências Sociais da PUC-Rio. Aprovada pela Comissão Examinadora abaixo assinada.
\end{abstract}

Prof ${ }^{\mathrm{a}}$ Cecília Martins de Mello

Orientadora

Departamento de História

PUC-Rio

Prof $^{a}$ Ana Paula Veiga Kiffer

Departamento de Letras

PUC-Rio

Prof. José da Costa Filho

Centro de Letras e Artes

UNIRIO

Prof $^{a}$ Patrícia Leal Azevedo Correa

Escola de Belas Artes

UFRJ

Prof $^{a}$ Joana Ribeiro da Silva Tavares

Centro de Artes e Letras

UNIRIO

Profa . Mônica Herz

Vice-Decana de Pós-Graduação do Centro de Ciências Sociais

PUC-Rio

Rio de Janeiro, 18 de agosto de 2010. 
Todos os direitos reservados. É proibida a reprodução total ou parcial do trabalho sem autorização da universidade, da autora e do orientador.

\section{Lucía Yáñez Silva}

Gradou-se em Artes Cênicas na Universidade Federal do Estado do Rio de Janeiro (UNIRIO) em 1999. Obteve o título de Mestre em Teatro na mesma universidade em 2003.

Ficha Catalográfica

Silva, Lucía Yañez

O rumor do corpo na deriva das palavras: uma reflexão sobre as relações entre o corpo e a escrita a partir do trabalho de Juan Dominguez / Lucía Yañez Silva; orientadora: Cecília Martins de Mello. - 2010.

240 f.: il. (color.); $30 \mathrm{~cm}$

Tese (doutorado) - Pontifícia Universidade Católica do Rio de Janeiro, Departamento de História, 2010.

Inclui bibliografia

1. História - Teses. 2. História social da cultura. 3. Corpo. 4. Escrita. 5. Coreografia contemporânea. 6. Domínguez, Juan. I. Mello, Cecília Martins de. II. Pontifícia Universidade Católica do Rio de Janeiro. Departamento de História. III. Título. 


\section{Agradecimentos}

À Professora Cecília Cotrim pelo diálogo constante, a confiança nas minhas escolhas, e fundamentalmente pelo carinho e o rigor da sua orientação.

A Juan Dominguez pelas questões propostas em seus trabalhos e a imensa disposição para me auxiliar durante o processo de pesquisa.

Aos Professores José da Costa filho, Ana Paula Kiffer, Patrícia Corrêa e Joana Ribeiro pela participação na comissão avaliadora da tese.

Aos Professores Patrícia Corrêa e André Lepecki pela generosa contribuição no exame de qualificação do projeto.

A Capes, à Puc-Rio e ao DAAD pelos auxílios concedidos.

A Edna Maria Timbó e aos demais e funcionários e docentes do Programa de Pósgraduação em Historia Social da Cultura.

Ao Institut für Theaterwissenschaft (FU Berlin), à Professora Gabriele Brandstetter e à sua cordial secretária - Inka M.Paul - por viabilizarem minha estadia de pesquisa em Berlim.

A Ana Paula Yáñez pelo amor fraterno, o estímulo constante, a troca inestimável e a cuidadosa leitura do trabalho.

À Ayara Hernández, Claudia Dias Sampaio, Valeska Figueiredo e Tatiana Melitello pelas valiosas conversas e as profundas manifestações de amizade.

A Chico Jofilsan pela paciência, o estímulo, o amor e o companheirismo.

Aos meus pais, irmãos, sogros e cunhados pelo afeto e os distintos gestos de cooperação brindados ao longo desta empreitada. 


\section{Resumo}

Yáñez Silva, Lucía; Mello, Cecília Martins de. O rumor do corpo na deriva das palavras: uma reflexão sobre as relações entre o corpo e a escrita a partir do trabalho de Juan Domínguez. Rio de Janeiro, 2010, 240 p. Tese de Doutorado - Departamento de História, Pontifícia Universidade Católica do Rio de Janeiro.

Este estudo propõe uma reflexão acerca das relações entre o corpo e a escrita na coreografia contemporânea a partir dos desdobramentos críticos sugeridos pela obra do artista espanhol Juan Domínguez. Os trabalhos intitulados Todos os bons espiões têm minha idade (2003) e The Application (2005) servem de ignição para esquadrinhar e problematizar esta equação, procurando exprimir a densidade desta questão. O primeiro capítulo examina distintos registros atrelados à prática coreográfica - desenhos, instruções, partituras, notações, e outros rascunhos afins -, assinalando a potência poética deste corpus para além da sua inerente função mnemônica e catalisadora, e expõe o debate crítico sobre a palavra escrita nas práticas artísticas contemporâneas. O segundo capítulo discute as relações entre as práticas coreográficas e a escrita pessoal - concebida, neste contexto, como um repertório que compreende as notas autobiográficas, as cartas, os diários, e outras narrativas análogas - examinando como a experiência cotidiana e a criação artística se afetam reciprocamente. O terceiro capítulo avalia algumas das abordagens do corpo verificadas no âmbito da dança, das ciências e da filosofia recente, evidenciando a emergência de uma perspectiva capaz de apreender o caráter intensivo do corpo e de pensar a escrita como uma prática sensível.

\section{Palavras-chave}

Corpo; Escrita; Coreografia Contemporânea; Juan Domínguez 


\section{Abstract}

Yáñez Silva, Lucía; Mello, Cecília Martins de (Advisor). The body’s rustle in the words' flow: a reflection upon the relations between body and writing suggested by Juan Domínguez's work. Rio de Janeiro, 2010, 240 p. PhD Dissertation - Departamento de História, Pontifícia Universidade Católica do Rio de Janeiro.

This study proposes a reflection on the relations between body and writing in contemporary choreography from the critical developments suggested by the work of Spanish artist Juan Domínguez. The pieces All good spies are my age (2003) and The Application (2005) provide a spark to probe and question this equation, in order to express the density of this issue. The first chapter examines different records tied to the chorographical practice - drawings, instructions, scores, notations, and other related outlines - stressing the power of this poetic corpus besides their catalyst and mnemonic innate functions, and outlines the critical debate about the written word in contemporary art. The second chapter discusses the relation between chorographical practices and personal writing - conceived, in this context, as a set that includes diaries, autobiographical notes, letters, and other related narratives - scrutinizing how the everyday experience and artistic creation are mutually affected. The third chapter reviews some of the available approaches of the body within dance field, sciences, and recent philosophy, highlighting the emergence of a perspective able to grasp the intensive nature of the body and to consider writing as a sensitive practice.

\section{Keywords}

Body; Writing; Contemporary Choreography; Juan Domínguez 


\section{Sumário}

1. Introdução 12

1.1 Introdução 12

$\begin{array}{ll}1.2 \text { Juan Domínguez por Juan Domínguez } & 18\end{array}$

$\begin{array}{ll}1.3 \text { Todos os bons espiões têm minha idade } & 19\end{array}$

$\begin{array}{ll}1.4 \text { The Application } & 27\end{array}$

2. Partituras, desenhos, notas e instruções 44

2.1 Fugacidade versus Inscrição 44

2.2 Still Acts $\quad 52$

2.3 O tempo em imagens 56

2.4 Temporalidade revisitada: diálogos inevitáveis 62

2.5 A partitura expandida 80

2.6 Uma questão de palavras: notas sobre o debate crítico 94

3. Cotidiano e autoficção 103

3.1 Dança e escrita de si 103

3.2 O cotidiano e a escrita dos diários 111

3.3 A questão autobiográfica 118

3.4 O dispositivo cênico em pauta 121

$3.5 \mathrm{O}$ quem da autobiografia 126

$\begin{array}{ll}3.6 \text { Autoficção } & 129\end{array}$

$\begin{array}{ll}\text { 3.7 Palestras e auto-entrevistas. } & 135\end{array}$

4. Corpos dançantes e escrita rizomática 150

4.1 Corpos que dançam 150

4.2 Corpo anatomo-fisilógico 156

$\begin{array}{ll}4.3 \text { O organismo } & 167\end{array}$ 
4.4 Corpo intensivo

4.5 Corpo paradoxal

4.6 Corpo e escrita

5 Conclusão

189

6 Referências Bibliográficas 


\section{Lista de Figuras}

Figura 1 - J. Domínguez. Todos os bons espiões têm minha idade 19

Figura 2 - J. Domínguez. Todos os bons espiões têm minha idade 20

Figura 3 - J. Domínguez. Todos os bons espiões têm minha idade 21

Figura 4 - J. Domínguez. Todos os bons espiões têm minha idade 23

Figura 5 - J. Domínguez. Todos os bons espiões têm minha idade 25

Figura 6 - J. Domínguez. Todos os bons espiões têm minha idade 26

Figura 7 - J. Domínguez. The Application 29

Figura 8 - J. Domínguez. The Application 31

Figura 9 - J. Domínguez. The Application 35

Figura 10 - J. Domínguez. The Application 37

Figura 11 - J. Domínguez. The Application 41

Figura 12 - J. Domínguez. The Application 42

Figura 13 - Martin Nachbar e Jochen Roller. Mnemonic Nonstop:

Ein Kartographisches Duett (2005) 50

Figura 14 - La Ribot. Panoramix (2003) 61

Figura 15 - Yvonne Rainer. Parts of Some Sextets (1965) 69

Figura 16 - Eadweard Muybridge. Animal Locomotion (1887) 70

Figura 17 - Trisha Brown. Spanish Dance / Accumulation Pieces 72 (1973)

Figura 18 - Bruce Nauman. Dance or Exercise on the Perimenter of a Square (1967-68)

Figura 19 - John Cage. 4'33" 3 versão da partitura. (1952) 82

Figura 20 - Trisha Brown. Sem Título (1975) 88

Figura 21 - Johnatan Burrows e Matteo Fargion. Both Sitting Duet 91 (2002)

Figura 22 - Vaslav Nijinski. Figuras Geométricas. s/d e Bailarina ou O Deus da dança. s/d

Figura 23 - Xavier Le Roy. Self Unfinished (1998) 
Tengo delante de mí una página de manuscrito; se pone en marcha algo que participa a la vez de la percepción, de la intelección y de la asociación - pero también de la memoria y el goce -, y que llamamos lectura. ¿Dónde voy a detener, o dónde puedo detener esa lectura? Sin duda, veo bien de que espacio parte mi ojo; ¿pero hacia qué? [...] ¿Cuáles son los planos que toda lectura descubre? Cual singular cosmonauta atravieso muchos mundos sin detenerme en ninguno: la blancura del papel, la forma de los signos, la figura de las palabras, las reglas de la lengua, las obligaciones del mensaje, la profusión de los sentidos asociados. Mismo viaje infinito, en otra dirección, a lo largo del que escribe: partiendo de la palabra escrita, podría remontarme a la mano, al músculo, a la sangre, a la pulsión, a la cultura y al goce del cuerpo. Por ambas partes, la lectura-escritura se expande hasta el infinito, compromete a todo el hombre, a su cuerpo y a su historia; es un acto pánico cuya única definición segura es que no se detiene en ninguna parte.

Roland Barthes. ${ }^{1}$

\footnotetext{
${ }^{1}$ BARTHES, Roland. "Variaciones sobre la escritura" In: BARTHES, Roland. Variaciones sobre la escritura. Barcelona, Buenos Aires, México: Paidós Comuniación, 2002
} 